\title{
Evento Zen: um Evento que Favorece a Humanização, Inclusão Social e Difusão da Aplicação das Práticas Integrativas e Complementares em Saúde Mental
}

\author{
Takeda, Osvaldo Hakio; Medeiros, Rafaela Sales; Nascimento, Maria Helena F. do; Cruz, \\ Michele Santos da; Scanavino, Marco de Tubino; Sant, Renato Del \\ Hospital Dia do IPqHCFMUSP — hakiot@hotmail.com
}

Introdução:O Zen é um evento aberto à população que acontece anualmente num serviço de saúde mental desde 2008 em São Paulo, e consiste no oferecimento de diferentes Práticas Integrativas e Complementares em Saúde - PICS (ex. shiatsu, kundalini yoga) que favorecem o restabelecimento das condições físicas e mentais. de acordo com nosso conhecimento atual, é o primeiro projeto brasileiro em Saúde Mental, utilizando as PICS que estimula a humanização do ambiente terapêutico, a partir do envolvimento dos profissionais, da população e dos pacientes no mesmo ambiente. Objetivos:Difundir o conhecimento da funcionalidade das PICS como modalidades auxiliares ao tratamento de condições mórbidas mentais à população e aos pacientes; integrar num ambiente humanizado profissionais da saúde mental, pacientes e a população; oferecer a oportunidade da vivência de um atendimento por meio de uma ou mais PICS. Métodos:É realizado anualmente em uma data pré-estabelecida, das $8 \mathrm{~h}$ às $16 \mathrm{~h}$. a coordenação é formada por 2 membros do serviço, os quais iniciam reuniões preparatórias 8 meses antes do evento. As reuniões são voltadas para definir processos de captação de recursos, elaboração e distribuição de material de divulgação, seleção das PICS e das pessoas que auxiliarão na logística do evento enquanto "staff". Os recursos captados são destinados ao custeio do material de divulgação, da decoração, lanche para os terapeutas e membros do "staff", som, iluminação, camisetas customizadas. ao final do evento os participantes entregam uma avaliação de opinião em que descrevem suas percepções e sugestões, as quais são analisadas posteriormente pela Equipe. Resultados:Contamos com 60 terapeutas voluntários, além de profissionais e pacientes do serviço como "staff'. As atividades foram: Shiatsu; Reflexologia; Reiki; TISE; Quick Massage; Kundalini Yoga e Tai Chi Chuan. Considerando os seis eventos realizados de 2008 a 2013; contabilizam-se aproximadamente 2.500 atendimentos já realizados. o resultado da pesquisa de opinião aplicada foi de que $100 \%$ das pessoas atendidas referiu elevada satisfação com a participação no Evento. Os pacientes salientaram o sentimento de valorização ao participarem da organização em situação igualitária com os profissionais e terapeutas. Conclusões:A promoção de eventos como esse, que por meio das mais variadas PICS, proporciona benefícios para todos os envolvidos, ao mesmo tempo em que divulga o papel das mesmas como auxiliares no tratamento de transtornos mentais, combate 0 estigma contra a doença mental, humanizando o ambiente terapêutico no qual pacientes, profissionais e população estão inseridos num contexto terapêutico que fomenta a inclusão social e promove o desenvolvimento humanístico dos pacientes, profissionais e da população.

Takeda, Osvaldo Hakio; Medeiros, Rafaela Sales; Nascimento, Maria Helena F. do; Cruz, Michele Santos da; Scanavino, Marco de Tubino; Sant, Renato Del. Evento Zen: um Evento que Favorece a Humanização, Inclusão Social e Difusão da Aplicação das Práticas Integrativas e Complementares em Saúde Mental.. In: Anais do Congresso Internacional de Humanidades \& Humanização em Saúde [= Blucher Medical Proceedings, num.2, vol.1]. São Paulo: Editora Blucher, 2014. ISSN 2357-7282

DOI 10.5151/medpro-cihhs-10593 